\title{
(2) OPEN ACCESS \\ What does the COVID-19 leadership experience teach us about healthcare leadership development?
}

\author{
Eren Behget (10), Chetna Modi
}

- Additional supplemental material is published online only. To view, please visit the journal online (http://dx.doi. org/10.1136/leader-2021000497).

Leadership and Lifelong Learning, NHS England and NHS Improvement London, London, UK

\section{Correspondence to}

Eren Behget, Leadership and Lifelong Learning, NHS England and NHS Improvement London, London, SE1 6LH, UK: eren.behget@ leadershipacademy.nhs.uk

Received 6 April 2021 Accepted 3 November 2021

Check for updates

(c) Author(s) (or their employer(s)) 2021. Re-use permitted under CC BY-NC. No commercial re-use. See rights and permissions. Published by BMJ.

To cite: Behget $\mathrm{E}$, Modi $\mathrm{C}$. $B M J$ Leader Published Online First: [please include Day Month Year]. doi:10.1136/ leader-2021-000497

\section{INTRODUCTION}

In January 2020, the UK started to see its first cases of COVID-19 and by 26 May 2020, it had recorded 37332 deaths. ${ }^{1}$ This first wave was just the beginning, and by 11 March 2021, the death rate had escalated to $125801 .^{1}$ First wave analyses showed that there were increased risks for men and women working in social care, and an increased risk for men in healthcare professions. ${ }^{2}$ The data suggested that there needed to be greater focus on supporting staff who were working in these difficult conditions.

Indeed, many organisations and publishers quickly shared a wealth of information, experiences and lessons about leadership in healthcare through a range of mediums including blog posts, peerreviewed articles and videos. Thus, this article aims to produce a commentary on some of the common threads in the sources and offers some suggestions as to what this could mean for leadership development in healthcare going forward.

\section{METHOD}

To build a literature base for this commentary, a hybrid approach of conventional and nonconventional methods was used to capture the wealth of information and identify some common threads within them. This is because more traditional methods for congregating literature would have typically omitted an abundance of information being shared (ie, in videos). The steps are outlined in greater detail in the following sections.

\section{Step 1: identifying sources}

As there were no known databases that collected non-scholarly and scholarly works, including videos and opinion pieces, the authors listed organisations and publishers which are well-known in the UK for sharing lessons, experiences and research on leadership in the healthcare context.

After searching their websites to verify that information was available, four sources were selected, which were: the BMJ Leader, the Kings Fund, the British Psychological Society and National Health Service (NHS) Confederation. These sources were selected because of the availability of information and due to the feasibility of reviewing the information rapidly.

\section{Step 2: selecting key works}

The search for key works involved two phases to ensure appropriate coverage of works. The first phase of the search was completed in August 2020, by just one researcher, where broad inclusion and exclusion criteria were applied.

The second phase was completed in July 2021, where two sets of researchers independently applied the search strategy to reduce chances of errors or bias. Works produced before 1 January 2020 and after 26 May 2020 were excluded, as well as any works which were press releases, podcasts, news articles, strategic documents, marketing materials or event information.

The resulting database of works was then screened by one researcher to include those which: contained specific advice for leaders or from leaders; were relevant to healthcare organisations and were related to COVID-19. This resulted in 77 works being identified in total. To see more information on the steps taken for the search strategy and its rationale, please refer to online supplemental material 1.

\section{Step 3: identification and synthesis of key messages}

A thematic analysis in line with the steps established by Braun and Clarke ${ }^{3}$ was used to identify and synthesise key messages in the included works. This was used as it is a flexible method that allows researchers to answer a range of questions in various ways to best suit their purpose, while also maintaining rigour through a transparent and clearly outlined process. ${ }^{34}$

The analysis did not aim to represent full coverage of the articles, but instead aimed to identify some key messages that could inform this commentary. The analysis was inductive, with codes and themes deriving from the data. Codes were created in line with the following question: 'what could be learnt about leadership in healthcare during the first peak of COVID-19?'. Codes constituted a theme when there appeared to be a meaningful lesson about leadership which was supported by multiple sources. An initial phase of theming was completed in August 2020. Then, in August 2021 following the updated search strategy, any new articles that were identified were added to the analysis, and any articles which were no longer included were removed.

In total, 58 articles were used for theming as they contributed towards a significant lesson about leadership. Fifteen of these works are included in this article as they represent the key points. The updated search strategy did not identify any new themes, as the codes that were created either fell into existing themes or were not prominent enough to constitute one, suggesting that saturation of key messages had been reached. Please see online supplemental 
material 2 for the theming tables, thematic map and a list of the additional works that were used.

\section{Step 4: commentary}

After the themes were derived, a commentary for each theme was given where critical reflections were provided to indicate what this could mean for leadership development going forward.

\section{FINDINGS}

Five overarching themes were derived from the synthesis, which prompted a number of considerations for leadership development.

\section{Creating systems for support}

Supporting others was considered as imperative for leaders to enact throughout the first wave and beyond. Showing compassion, ${ }^{5}$ keeping an eye on the workloads of staff $^{5}$ and formal stepped psychological care were emphasised. ${ }^{6}$ While many more behaviours were proposed, it was also highlighted that senior leaders were going through significant challenges too. ${ }^{7}$ Accordingly, ways to engage in self-care were widely reported, including allowing others to take the lead and planning time for recuperation. $^{89}$

However, it was noted by the British Psychological Society's COVID-19 staff well-being group that staff may neglect self-care because it is not seen as a primary concern. ${ }^{6}$ Consideringly, a point made by James Mountford appears particularly important to note: he highlighted the importance of leaders implementing systems that protect staff well-being. ${ }^{8}$ This could mean that leaders who are supporting others could also have greater opportunities to support themselves, as the onus is transferred to the organisation. ${ }^{8}$

Taken together, there may be some value in leadership development initiatives exploring ways to support the normalisation of self-care activities. They could also draw on existing research, such as one study in the USA which found that commonly held beliefs were influential for emergency physicians to feel comfortable to engage in break taking and self-care. ${ }^{10}$ Leaders could also be equipped to influence organisations to develop protective mechanisms and systems for staff well-being through new policies and procedures, and ultimately place greater responsibility on organisations to do more for their staff by default.

\section{The possibilities and dangers of working with urgency}

Considering the imminent and increasingly devastating potential of the virus, articles reported staff working at speed and with selflessness to save as many lives as possible. ${ }^{11} 12$ As such, gold and silver command centres were created, and there were examples of more top-down behaviours being enacted. ${ }^{12}$

While this may have had some benefits for the situation, Trimble recognised that some people were left feeling unable to speak, potentially perpetuating an already unequal system as some perspectives were not being heard. ${ }^{13}$ Touching on similar issues, Prerana Issar highlighted that working with urgency does not have to be at the expense of inclusivity. ${ }^{9}$ It should be remembered that they can coexist. ${ }^{9}$

Therefore, those tasked with research, design and development of programmes could benefit from incorporating more unique and critical perspectives into their work to reflect the need to cater for more complex ways of thinking about leadership. They could consider incorporating a paradox lens, ${ }^{14}$ or framing leadership approaches with greater contextual sensitivity. ${ }^{15}$ Providing awareness of these perspectives may prime leaders to consider a more dynamic approach to their practice, which may be better suited to the complexity that can often unfold in real-life settings. Similarly, leadership assessments could benefit from building in elements that consider these perspectives, such as recognising that not all leadership behaviours are ideal for all situations and that seemingly contrasting leadership approaches may be able to coexist.

\section{Integrating and mobilising multiagency systems}

The pandemic also highlighted some examples where organisations worked in partnership with people whom they had not worked with before. ${ }^{11}$ One example was where construction, healthcare and conference organisations worked together to develop hospitals in extraordinary time. ${ }^{11}$ Several sources explained that feats such as these may have only been possible because everyone, no matter which organisation they were from, had a strong common purpose. ${ }^{16} 17$

Other articles alluded to some factors which may have supported these organisations to stay connected and move forward more productively, including joint decision-making, ${ }^{17}$ overcoming challenges associated with information governance ${ }^{18}$ and active communication. ${ }^{19}$ However, the detail of these factors was not overtly described and it is not clear if this way of working and the readiness of people to come together were a result of the unique situation of COVID-19; or if similar ways of working will be possible in future emergency and nonemergency situations.

Consequently, it may be beneficial to develop leaders with the skills to establish effective goals and supply training on the mechanisms that may enhance multiagency working such as joint decision frameworks. It may also be beneficial for leadership researchers to explore the unknowns in greater detail. For instance, it could be helpful to understand if people deviated or followed existing guidance intended to support multiagency working and explore the reasons why. Once understood, training on these insights could support leaders to be more prepared for future situations and be more ready to adapt to the nuances that may exist in different contexts.

\section{Leading consistently for equality, diversity and inclusion}

Around April 2020, sources started to report that the pandemic was having a disproportionate impact on people from ethnic minority backgrounds, even when controlling for a range of factors such as age. ${ }^{20}$ It was noted by Bailey and West in a Kings Fund post that these trends could be symptomatic of systemic discrimination inherent in society and workplaces. ${ }^{21}$

There were also indications from some articles on how to make progress on this issue, from individual behaviours such as showing compassion, ${ }^{21}$ to more organisational-level actions such as taking steps to ensure diversity in decision-making at every level. ${ }^{22}$ However, if the root of this problem is systemic, then changes may be needed across the healthcare system and beyond, and inclusive behaviours may need to be consistently enacted in order for meaningful change to be made and sustained. Indeed, a previous paper on structural racism and health inequalities highlighted the importance of understanding and influencing the wider context in which healthcare systems operate. ${ }^{23}$ This report also suggested the importance of healthcare professionals engaging in continuous self-reflection and learning about how structural racism could be being perpetuated, as well as ways to make progress. $^{23}$

Thus, leadership development programmes may not only benefit from encouraging some of the actions cited, but also 
emphasising the importance of leaders being consistent in their behaviour, self-reflecting and developing skills to influence in the wider context that their healthcare system operates. ${ }^{23}$ Not only this, it may be impactful for training and development professionals themselves to critically self-reflect and consider how structural racism may be being perpetuated and how it may be alleviated across the whole training cycle, from areas such as procurement to evaluation. Coaching may also be a helpful development process which leaders can engage in to support their reflection. Indeed, the evidence suggests that coaching is an effective intervention for a range of outcomes, ${ }^{24}$ but the extent of its usefulness for this and similar challenges may depend on the expertise of the coach, and if the leader can find the time for coaching in a crisis.

\section{The importance of continuous learning}

Finally, the importance of continuous learning was mentioned by a range of leaders in the NHS, including Niall Dickson in a comment piece for NHS confederation, who noted the importance of capturing examples of good practice for future learning. ${ }^{25}$ Prerana Issar, in a video for the Kings Fund, also added the importance of leaders supporting environments and cultures that encourage learning, while inhibiting blame. ${ }^{9}$

As such, participants on leadership programmes may benefit from content that explores how they could enhance psychological safety in their teams which could help people to raise errors and learn from them. ${ }^{26}$ More specifically, Amy Edmondson's work may be of particular value, including the Leader toolkit which outlines some practical actions that leaders can take to create psychological safety, such as showing appreciation. ${ }^{26}$ Such principles could also be helpful to facilitators of leadership programmes, particularly where sensitive personal experiences provide the basis for learning. It may also be advantageous for leaders to attend groups where they can learn from their peers, for example, conferences, forums and symposiums. However, their participation is likely to be influenced by their external environment, such as the nature and phase of a crisis. Therefore, development providers should make active efforts to use different mediums for these learning forums to take place.

\section{DISCUSSION}

This commentary proposed a number of considerations for leadership development, informed by a synthesis of some of the key messages being shared during the first peak of the pandemic. The themes identified were: (1) creating systems for support, (2) the possibilities and dangers of working with urgency, (3) integrating and mobilising multiagency systems, (4) leading consistently for equality, diversity and inclusion, and (5) the importance of continuous learning. Suggestions for development activity ranged from incorporating more unique perspectives into programme designs to incorporating diversity and inclusion throughout the training cycle.

The themes also seem to support elements of previous leadership literature which considered leadership at times of crisis. Boin and colleagues explained 10 tasks which political or strategic leadership could be evaluated against. ${ }^{27}$ This included 'orchestrated cooperation across boundaries' which noticed that at times of crisis, those who are impacted can often self-organise effectively, and if they do, then those in senior positions should serve to remove obstacles and move away from commanding behaviours. ${ }^{27}$ While another task highlighted the importance of 'learning, ${ }^{27}$ Klann's book on crisis leadership also outlined that showing genuine concern and care for people is of utmost importance and to do so, leaders could set an example by caring for themselves. ${ }^{28}$ Therefore, this article adds to the reliability of some of these elements that were mentioned by previous authors.

However, it is also important to note the limitations of this work. The sources used tended to be UK-centric, did not consider those published in other languages, and did not consider the wealth of information that may have existed in an array of other journals and websites. The search for information was restricted to a small time period and to a selected few organisations and publishers who provided rapid information for people to reflect on and consider based on personal experiences, opinions, expertthought leadership and in some cases, previous theory and data.

While these were incredibly timely, it is currently unclear how these compare with the newer experiences, research, opinions and analyses, and those of which exist outside these organisations. Thus, it is likely that the thoughts and messages shared in this paper will not work for all people, in all situations, because the reality is likely to be much more complex and nuanced than has been described.

Second, this article did not take a traditional approach that would often be used to congregate information, that is, rapid review. Specifically, it did not restrict its search to just scholarly articles, and the works included did not go through any significant quality-appraisal process. While this means there could be more bias inherent in the information used and thus the conclusions made, it also means that attention could be brought to lessons that were being shared at a rapid pace and to some more unique perspectives that may otherwise have been missed.

Therefore, this article should only be used to prompt consideration for readers. Future research could build on the gaps described here and discuss methods, including improvements to the one used in this study, that can be used for more unusual times. Future research could also describe in detail the more granular actions that leaders could do in times of crisis, as this article focused on leadership behaviours at an aggregated level.

This leads to one final consideration for leadership development: leadership development programmes may benefit from emphasising the importance of critical thinking and analysis in leadership, so that future leaders are able to filter the abundance of information that they are likely to encounter. Ultimately, this helps them to distinguish what may work for them and for their unique situations. Indeed, critical thinking was also proposed by Wang and Berendt as an important process for clinical leaders to be practising, ${ }^{29}$ but we suggest that this may also be helpful for leaders more broadly.

\section{CONCLUSION}

In all, there were a number of key messages that could be learnt about leadership from the first wave, and this commentary suggests a number of considerations for leadership development. These considerations include supporting the normalisation of self-care activities, incorporating unique and critical perspectives into designs, exploring the detail behind working in multiagency teams, considering diversity and inclusion throughout the training cycle and creating safe spaces where people are able to learn. This article also brought attention to how crucial it may be for leaders to use critical thinking when learning, especially in a world where there is an abundance of information, to determine what may work for their own unique experiences. In this vein, leaders are encouraged to not just take this article at face value, but also carefully deliberate this article, its themes and its conclusions. 
Twitter Chetna Modi @ChetnaModi3

Acknowledgements We would like to thank Dr Tim Swanwick, Niomie Warner, Dr Sam Jee and Lisa Gibbins for their support and encouragement throughout this work.

Contributors EB and CM conceptualised this work. EB applied the search strategy and screened the results. Dr Sam Jee and Lisa Gibbins worked independently from EB to also apply the search strategy to ensure full coverage of works. EB coded and themed the works and drafted an initial article. CM critically revised the article.

Funding The authors have not declared a specific grant for this research from any funding agency in the public, commercial or not-for-profit sectors.

Disclaimer This article represents the views of the authors and not necessarily the views of the NHS.

Competing interests Both authors work within NHS England and Improvement's People Directorate, Leadership and Lifelong Learning team. EB is a graduate member of the British Psychological Society.

Patient consent for publication Not required.

Provenance and peer review Not commissioned; externally peer reviewed.

Supplemental material This content has been supplied by the author(s). It has not been vetted by BMJ Publishing Group Limited (BMJ) and may not have been peer-reviewed. Any opinions or recommendations discussed are solely those of the author(s) and are not endorsed by BMJ. BMJ disclaims all liability and responsibility arising from any reliance placed on the content. Where the content includes any translated material, BMJ does not warrant the accuracy and reliability of the translations (including but not limited to local regulations, clinical guidelines, terminology, drug names and drug dosages), and is not responsible for any error and/or omissions arising from translation and adaptation or otherwise.

Open access This is an open access article distributed in accordance with the Creative Commons Attribution Non Commercial (CC BY-NC 4.0) license, which permits others to distribute, remix, adapt, build upon this work non-commercially, and license their derivative works on different terms, provided the original work is properly cited, appropriate credit is given, any changes made indicated, and the use is non-commercial. See: http://creativecommons.org/licenses/by-nc/4.0/.

ORCID iDs

Eren Behget http://orcid.org/0000-0003-4322-7697

Chetna Modi http://orcid.org/0000-0003-2859-5547

\section{REFERENCES}

1 Gov.uk. Coronavirus (COVID-19) in the UK - deaths. Available: https://coronavirus. data.gov.uk/details/deaths [Accessed 17 Nov 2021].

2 Office for National Statistics (ONS). Coronavirus (COVID-19) related deaths by occupation, England and Wales: deaths 9 March and 25 may 2020. Available: https:// www.ons.gov.uk/peoplepopulationandcommunity/healthandsocialcare/causesofdeath/ bulletins/coronaviruscovid19relateddeathsbyoccupationenglandandwales/deathsre gisteredbetween9marchand25may2020\#deaths-involving-covid-19-among-men-andwomen-health-and-social-care-workers [Accessed 18 Mar 2021].

3 Braun V, Clarke V. Using thematic analysis in psychology. Qual Res Psychol 2006;3:77-101.

4 Dixon-Woods M, Agarwal S, Jones D, et al. Synthesising qualitative and quantitative evidence: a review of possible methods. J Health Serv Res Policy 2005;10:45-53.

5 Bailey S, West M. COVID-19: Why compassionate leadership matters in a crisis. The Kings Fund. Available: https://www.kingsfund.org.uk/blog/2020/03/covid-19-crisiscompassionate-leadership [Accessed 18 Mar 2021].

6 Highfield J, Johnstone E, Jones T. The British Psychological Society COVID-19 Staff Well-Being Group - The psychological needs of healthcare staff as a result of the Coronavirus outbreak. British Psychological Society, 2020. Available: https://www. bps.org.uk/news-and-policy/psychological-needs-healthcare-staff-result-coronaviruspandemic [Accessed 19 Mar 2021].
7 Pandit M, Berendt AR. Ten minutes with Professor Meghana Pandit, chief medical officer, Oxford university hospitals NHS Foundation trust. BMJ Leader 2020;4:246-7.

8 Mountford J, Berendt AR. Ten minutes with James Mountford, chief of quality and learning, NHS Nightingale Hospital London. BMJ Leader 2020;4:151-3.

9 Prerana I. Why is leadership important right now? Prerana Issar, Chief People Officer, NHS. The Kings Find, 2020. Available: https://www.kingsfund.org.uk/audio-video/ why-leadership-important-covid-prerana-issar [Accessed 19 Mar 2021].

10 O'Shea J, Vu S, Siegelman J, et al. "Breaking" the Emergency Department: Does the Culture of Emergency Medicine Present a Barrier to Self-Care? West J Emerg Med 2020;21:313-21.

11 Wallace I, Berendt AR. Ten minutes with Dr lain Wallace, medical director, NHS Louisa Jordan Hospital, Scottish events campus (Sec), Glasgow. BMJ Leader 2020;4:147-8.

12 Dalton SD. Flapjack or jackboot? reflections on leadership styles for the COVID-19 pandemic. BMJ Leader 2020;4:99-100.

13 Trimble A. The impact of COVID-19 on working relationships. The Kings Fund, 2020. Available: https://www.kingsfund.org.uk/blog/2020/05/impact-covid-19-workingrelationships [Accessed 18 Mar 2021].

14 Lewis MW, Smith WK. Paradox as a metatheoretical perspective: sharpening the focus and widening the scope. The Journal of Applied Behavioral Science 2014;50:127-49.

15 Hannah ST, Sumanth JJ, Lester P, et al. Debunking the false dichotomy of leadership idealism and pragmatism: critical evaluation and support of newer genre leadership theories. J Organ Behav 2014;35:598-621.

16 Harchowal J. Creating a common purpose and a supportive culture: Jatinder Harchowal. The Kings Fund, 2020. Available: https://www.kingsfund.org.uk/audiovideo/common-purpose-culture-jatinder-harchowal [Accessed 18 Mar 2021].

17 Jain R. NHS Reset: The benefits of integration during COVID-19: Raj Jain. NHS Confederation, 2020. Available: https://www.nhsconfed.org/articles/nhs-resetbenefits-integration-during-covid-19 [Accessed 21 Aug 2021].

18 Humphries R. Integrating health and social care in the COVID-19 (coronavirus) response. The Kings Fund, 2020. Available: https://www.kingsfund.org.uk/blog/2020/ 04/health-social-care-covid-19-coronavirus [Accessed 21 Aug 2021].

19 Stoller JK. Reflections on leadership in the time of COVID-19. BMJ Leader 2020:4:77-9.

20 Office for National Statistics (ONS). Coronavirus (COVID-19) related deaths by ethnic group, England and Wales: 2 March 2020 to 10 April 2020. Available: https://www. ons.gov.uk/peoplepopulationandcommunity/birthsdeathsandmarriages/deaths/ articles/coronavirusrelateddeathsbyethnicgroupenglandandwales/2march2020to10ap ril2020 [Accessed 19 Mar 2021].

21 Bailey S, West M. Ethnic minority deaths and COVID-19: what are we to do? the kings fund, 2020. Available: https://www.kingsfund.org.uk/blog/2020/04/ethnic-minoritydeaths-covid-19 [Accessed 18 Mar 2021].

22 Allen S, Evans N, Webster R. Equality, diversity and inclusion at a time of crisis and beyond: Sam Allen, Dr Navina Evans, Rob Webster. NHS Confederation, 2020. Available: https://www.nhsconfed.org/articles/equality-diversity-and-inclusion-timecrisis-and-beyond [Accessed 20 Aug 2021].

23 Bailey ZD, Krieger N, Agénor $M$, et al. Structural racism and health inequities in the USA: evidence and interventions. Lancet 2017;389:1453-63.

24 Jones RJ, Woods SA, Guillaume YRF. The effectiveness of workplace coaching: a metaanalysis of learning and performance outcomes from coaching. J Occup Organ Psychol 2016;89:249-77.

25 Dickson N. NHS Reset: Rethinking the future. NHS Confederation, 2020. Available: https://www.nhsconfed.org/articles/nhs-reset-rethinking-future [Accessed 21 Aug 2021].

26 Edmondson AC. The fearless organization: creating psychological safety in the workplace for learning, innovation and growth. Hoboken, NJ: John Wiley \& Sons, Inc, 2019.

27 Boin A, Kuipers S, Overdijk W. Leadership in times of crisis: a framework for assessment. International Review of Public Administration 2013;18:79-91.

28 Klann G. Crisis leadership: using military lessons, organizational experiences, and the power of influence to lessen the impact of chaos on the people you lead. Greensboro, NC: CCL Press, 2003

29 Wang L, Berendt A. Ten minutes with Dr Linghang Wang, director of infectious diseases emergency, Deputy director of the research Institute of infectious diseases, Beijing Ditan Hospital. BMJ Leader 2020;4:94-5. 